\title{
Numerical simulation on the effect of fractures geometries for shale gas development with discrete fracture network model
}

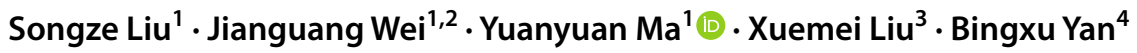

Received: 17 October 2020 / Accepted: 6 January 2021 / Published online: 17 February 2021

(c) The Author(s) 2021

\begin{abstract}
The shale gas reservoir is regarded as a dual medium consisting of fracture (hydraulic fracture and discrete natural fracture network) and rock matrix, the seepage process in the fracture and rock matrix is fully considered and a mathematical model of seepage flow in accordance with Darcy's law was established. The results show the influence order of hydraulic fracture geometry on the cumulative production. Compared with the hydraulic fracture aperture of $10^{-4} \mathrm{~m}$, when the aperture is $10^{-5} \mathrm{~m}$ and $10^{-6} \mathrm{~m}$, the cumulative production is reduced by $88.0 \%$ and $99.7 \%$, respectively. Compared with the hydraulic fracture length is $100 \mathrm{~m}$, when the length is $200 \mathrm{~m}$ and $300 \mathrm{~m}$, the cumulative production is increased by $38.2 \%$ and $62.4 \%$, respectively. The increase in the natural fracture aperture increases the fracture permeability, which make it more conducive to gas flow into the fracture, thereby increasing the cumulative production. The increase in the number of natural fractures makes the connectivity of the shale reservoir becomes better and the cumulative production increases more.
\end{abstract}

Keywords Shale gas $\cdot$ Hydraulic fracture $\cdot$ Discrete natural fracture network $\cdot$ Fracture geometry $\cdot$ Numerical simulation

\section{List of symbols}

df Hydraulic fracture aperture, $\mathrm{mm}$

$\mathrm{Nf} \quad$ Hydraulic fracture number

Lf Hydraulic fracture length, $m$

Angle Angle between hydraulic fracture and the horizontal well, ${ }^{\circ}$

Dnf Natural fracture aperture, $\mathrm{mm}$

Nnf Natural fracture number

Lnf Natural fracture length, $m$

$\rho \quad$ Gas density, $\mathrm{kg} / \mathrm{m}^{3}$

$S_{\mathrm{m}} \quad$ Matrix storage coefficient, $1 / \mathrm{Pa}$

$p \quad$ Pore pressure, $\mathrm{Pa}$

Jianguang Wei

3106097170@qq.com

Yuanyuan Ma

mayuanyuan_1991@outlook.com

1 Department of Petroleum Engineering, Northeast Petroleum University, Daqing, China

2 Key Laboratory of Continental Shale Hydrocarbon Accumulation and Efficient Development (Northeast Petroleum University), Ministry of Education, Daqing, China

3 Oil Production Plant, PetroChina Daqing Oilfield No, Daqing, China

4 PetroChina Tarim Oilfield Exploration and Development Research Institute, Korla, China $t \quad$ Time, $\mathrm{s}$

$u \quad$ Gas flow velocity in matrix, $\mathrm{m} / \mathrm{s}$

$M \quad$ Gas Molar mass, $\mathrm{kg} / \mathrm{md}$

$R \quad$ Ideal gas constant, $\mathrm{J} /(\mathrm{mol} \mathrm{K})$

$T \quad$ Environmental temperature, $\mathrm{K}$

$C_{\mathrm{g}} \quad$ Gas compression ratio, $1 / \mathrm{Pa}$

$C_{\mathrm{m}} \quad$ Rock matrix compression ratio, $1 / \mathrm{Pa}$

$\varphi \quad$ Matrix porosity

Z Gas compression factor

$\mathrm{V} \quad$ Gas volume, $\mathrm{m}^{3}$

$k_{\mathrm{m}} \quad$ Rock matrix permeability, $\mathrm{m}^{2}$

$\mu \quad$ Gas viscosity, Pa s

$\tau \quad$ Medium curvature

$\gamma \quad \tau$

$S_{\mathrm{f}} \quad$ Fracture storage coefficient, $1 / \mathrm{Pa}$

$w \quad$ Fracture aperture, $\mathrm{m}$

$u_{\mathrm{f}} \quad$ Gas flow velocity in fracture, $\mathrm{m} / \mathrm{s}$

$k_{\mathrm{f}} \quad$ Fracture permeability, $\mathrm{m}^{2}$

\section{Introduction}

Shale gas is an unconventional energy source which is stored in the reservoir rock series of organic shale in the form of adsorbed gas or free gas (Yuan et al. 2019; Zhang et al. 2015). After the formation of shale gas, it gathers 
in the vicinity of formation site. The shale is not only the source of production, but also the reservoir for storage and the caprocks for preserved. It is a typical "self-generated, in-situ accumulation" model (Li et al. 2018). Shale gas is one of the most popular clean, low-carbon emission emerging energy which has advantages of abundance and wide distribution (Shar et al. 2018; Sun et al. 2013; Zheng et al. 2016). Due to the low porosity and ultra-low permeability of shale gas reservoir (the porosity usually ranges from $1-3 \mathrm{~nm}$ to $400-700 \mathrm{~nm}$, the permeability is on the order of $10^{-8}-10^{-4} \mathrm{mD}$ ) the gas seepage resistance is extremely high and it is difficult to exploit shale gas by traditional methods (Wei et al. 2019; Zhang et al. 2019). Hydraulic fracturing technology is an efficient way to exploit shale gas currently (Cao et al. 2016; Ma et al. 2020a, b; Yaghoubi 2019). Fracture formed by hydraulic fracturing technology can provide enough storage space and migration channel for shale gas, improve the permeability of shale reservoir and increase shale gas production (Liu et al. 2015). The development process of shale gas involves the complex space-time evolution of seepage field in fractured rock (Fan et al. 2015; Xu et al. 2018). Numerical simulation is one of the key techniques to investigate this problem. The establishment of mathematical model to simulate the seepage field evolution process in fractured rock is of great significance for the formulation of shale gas development plan and solving the practical problems encountered in the development process (Cao et al. 2017). Common mathematical models mainly include discrete fracture model and equivalent continuum model (Ma et al. 2020c; Xu et al. 2019). The discrete fracture model is composed of a large number of fracture networks, which is closer to the actual reservoir. The application of this model to simulate the shale gas development process is more in line with the actual situation (Mi et al. 2014; Dai et al. 2019; Wang 2018). Domestic and foreign scholars have carried out a lot of beneficial exploration on numerical simulation of shale gas development (Kudapa et al. 2017; Mahmoud et al. 2020; Zhang et al. 2017), but it is not perfect enough as a whole. One of the key technical problems is how to simulate large-scale complex fracture network. Few studies have investigated both the effect hydraulic fracture and discrete natural fracture network on shale gas mining comprehensively. In this paper, the shale gas reservoir is regarded as a dual medium consisting of fracture (hydraulic fracture and discrete natural fracture network) and rock matrix, the seepage process in the fracture and rock matrix is fully considered and a mathematical model of seepage flow in accordance with Darcy's law was established. The velocity field distribution and pressure field distribution were analyzed under different mining time, the shale gas development process was simulated under different hydraulic and natural fractures geometries. The production rate and cumulative production were presented as evaluation indexes, the shale gas development effect under different fracture geometries was quantitatively evaluated.

\section{Model description}

\section{Computational model}

Figure 1 illustrates the schematic of the computational model. The size of the computational model is $1000 \mathrm{~m} \times 300 \mathrm{~m}$. The gray area represents the rock matrix and the blue line in the middle of the model represents the horizontal well. The red lines represent hydraulic fractures which are evenly distributed perpendicular to the horizontal well. The yellow lines represent natural fractures, the fracture length follows the normal distribution and the fracture angle follows the uniform distribution. A randomly generated fracture network can represent an anisotropic fractured rock statistically.

This study focuses on the effect of hydraulic fracture and natural fracture parameters on the development of shale gas, we proposed 32 Cases with different fracture aperture, the number of fractures, fracture length and

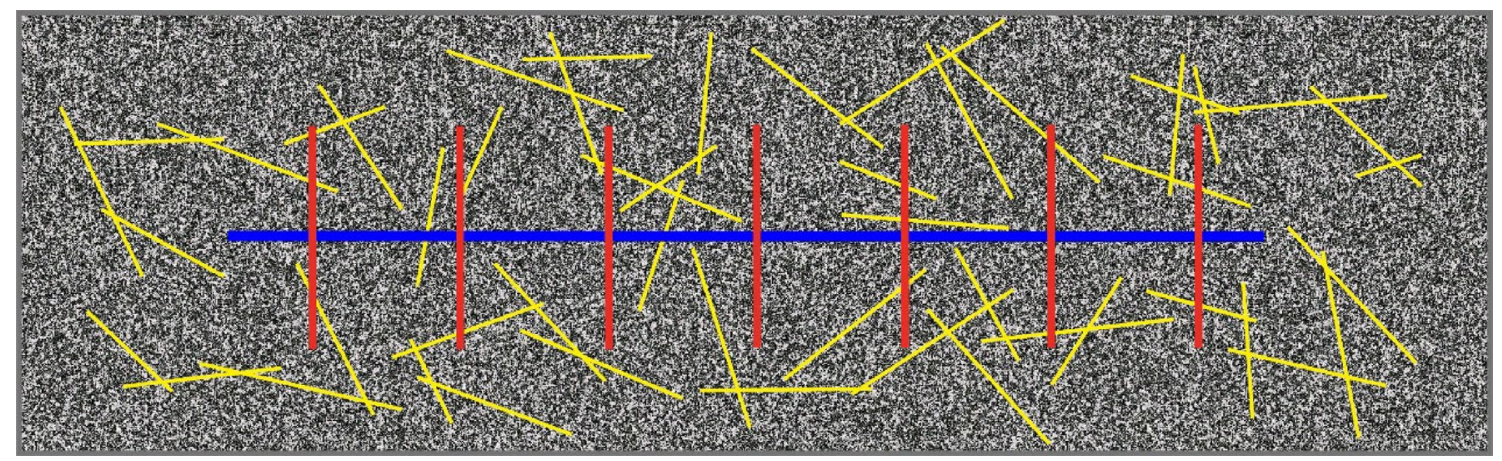

Fig. 1 The schematic of the computational model

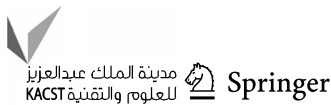


Table 1 Numerical simulation scheme of under different fracture parameters

\begin{tabular}{|c|c|c|c|c|c|c|c|}
\hline Case & df & $\mathrm{Nf}$ & Lf & Angle & $\operatorname{dnf}$ & $\mathrm{Nnf}$ & $\operatorname{Lnf}$ \\
\hline 1 & $10^{-4} \mathrm{~m}$ & 7 & $150 \mathrm{~m}$ & $90^{\circ}$ & $3.16 \times 10^{-5} \mathrm{~m}$ & 50 & $100 \mathrm{~m}$ \\
\hline 2 & $10^{-4} \mathrm{~m}$ & 7 & $150 \mathrm{~m}$ & $90^{\circ}$ & $10^{-6} \mathrm{~m}$ & 50 & $100 \mathrm{~m}$ \\
\hline 3 & $3.16 \times 10^{-5} \mathrm{~m}$ & 7 & $150 \mathrm{~m}$ & $90^{\circ}$ & $10^{-6} \mathrm{~m}$ & 50 & $100 \mathrm{~m}$ \\
\hline 4 & $10^{-5} \mathrm{~m}$ & 7 & $150 \mathrm{~m}$ & $90^{\circ}$ & $10^{-6} \mathrm{~m}$ & 50 & $100 \mathrm{~m}$ \\
\hline 5 & $3.16 \times 10^{-6} \mathrm{~m}$ & 7 & $150 \mathrm{~m}$ & $90^{\circ}$ & $10^{-6} \mathrm{~m}$ & 50 & $100 \mathrm{~m}$ \\
\hline 6 & $10^{-6} \mathrm{~m}$ & 7 & $150 \mathrm{~m}$ & $90^{\circ}$ & $10^{-6} \mathrm{~m}$ & 50 & $100 \mathrm{~m}$ \\
\hline 7 & $10^{-4} \mathrm{~m}$ & 4 & $150 \mathrm{~m}$ & $90^{\circ}$ & $3.16 \times 10^{-5} \mathrm{~m}$ & 50 & $100 \mathrm{~m}$ \\
\hline 8 & $10^{-4} \mathrm{~m}$ & 5 & $150 \mathrm{~m}$ & $90^{\circ}$ & $3.16 \times 10^{-5} \mathrm{~m}$ & 50 & $100 \mathrm{~m}$ \\
\hline 9 & $10^{-4} \mathrm{~m}$ & 6 & $150 \mathrm{~m}$ & $90^{\circ}$ & $3.16 \times 10^{-5} \mathrm{~m}$ & 50 & $100 \mathrm{~m}$ \\
\hline 10 & $10^{-4} \mathrm{~m}$ & 8 & $150 \mathrm{~m}$ & $90^{\circ}$ & $3.16 \times 10^{-5} \mathrm{~m}$ & 50 & $100 \mathrm{~m}$ \\
\hline 11 & $10^{-4} \mathrm{~m}$ & 9 & $150 \mathrm{~m}$ & $90^{\circ}$ & $3.16 \times 10^{-5} \mathrm{~m}$ & 50 & $100 \mathrm{~m}$ \\
\hline 12 & $10^{-4} \mathrm{~m}$ & 10 & $150 \mathrm{~m}$ & $90^{\circ}$ & $3.16 \times 10^{-5} \mathrm{~m}$ & 50 & $100 \mathrm{~m}$ \\
\hline 13 & $10^{-4} \mathrm{~m}$ & 7 & $100 \mathrm{~m}$ & $90^{\circ}$ & $3.16 \times 10^{-5} \mathrm{~m}$ & 50 & $100 \mathrm{~m}$ \\
\hline 14 & $10^{-4} \mathrm{~m}$ & 7 & $200 \mathrm{~m}$ & $90^{\circ}$ & $3.16 \times 10^{-5} \mathrm{~m}$ & 50 & $100 \mathrm{~m}$ \\
\hline 15 & $10^{-4} \mathrm{~m}$ & 7 & $250 \mathrm{~m}$ & $90^{\circ}$ & $3.16 \times 10^{-5} \mathrm{~m}$ & 50 & $100 \mathrm{~m}$ \\
\hline 16 & $10^{-4} \mathrm{~m}$ & 7 & $300 \mathrm{~m}$ & $90^{\circ}$ & $3.16 \times 10^{-5} \mathrm{~m}$ & 50 & $100 \mathrm{~m}$ \\
\hline 17 & $10^{-4} \mathrm{~m}$ & 7 & $150 \mathrm{~m}$ & $75^{\circ}$ & $3.16 \times 10^{-5} \mathrm{~m}$ & 50 & $100 \mathrm{~m}$ \\
\hline 18 & $10^{-4} \mathrm{~m}$ & 7 & $150 \mathrm{~m}$ & $60^{\circ}$ & $3.16 \times 10^{-5} \mathrm{~m}$ & 50 & $100 \mathrm{~m}$ \\
\hline 19 & $10^{-4} \mathrm{~m}$ & 7 & $150 \mathrm{~m}$ & $45^{\circ}$ & $3.16 \times 10^{-5} \mathrm{~m}$ & 50 & $100 \mathrm{~m}$ \\
\hline 20 & $10^{-4} \mathrm{~m}$ & 7 & $150 \mathrm{~m}$ & $30^{\circ}$ & $3.16 \times 10^{-5} \mathrm{~m}$ & 50 & $100 \mathrm{~m}$ \\
\hline 21 & $10^{-4} \mathrm{~m}$ & 7 & $150 \mathrm{~m}$ & $90^{\circ}$ & $10^{-4} \mathrm{~m}$ & 50 & $100 \mathrm{~m}$ \\
\hline 22 & $10^{-4} \mathrm{~m}$ & 7 & $150 \mathrm{~m}$ & $90^{\circ}$ & $10^{-5} \mathrm{~m}$ & 50 & $100 \mathrm{~m}$ \\
\hline 23 & $10^{-4} \mathrm{~m}$ & 7 & $150 \mathrm{~m}$ & $90^{\circ}$ & $3.16 \times 10^{-6} \mathrm{~m}$ & 50 & $100 \mathrm{~m}$ \\
\hline 24 & $10^{-4} \mathrm{~m}$ & 7 & $150 \mathrm{~m}$ & $90^{\circ}$ & $10^{-6} \mathrm{~m}$ & 50 & $100 \mathrm{~m}$ \\
\hline 25 & $10^{-4} \mathrm{~m}$ & 7 & $150 \mathrm{~m}$ & $90^{\circ}$ & $3.16 \times 10^{-5} \mathrm{~m}$ & 25 & $100 \mathrm{~m}$ \\
\hline 26 & $10^{-4} \mathrm{~m}$ & 7 & $150 \mathrm{~m}$ & $90^{\circ}$ & $3.16 \times 10^{-5} \mathrm{~m}$ & 75 & $100 \mathrm{~m}$ \\
\hline 27 & $10^{-4} \mathrm{~m}$ & 7 & $150 \mathrm{~m}$ & $90^{\circ}$ & $3.16 \times 10^{-5} \mathrm{~m}$ & 100 & $100 \mathrm{~m}$ \\
\hline 28 & $10^{-4} \mathrm{~m}$ & 7 & $150 \mathrm{~m}$ & $90^{\circ}$ & $3.16 \times 10^{-5} \mathrm{~m}$ & 125 & $100 \mathrm{~m}$ \\
\hline 29 & $10^{-4} \mathrm{~m}$ & 7 & $150 \mathrm{~m}$ & $90^{\circ}$ & $3.16 \times 10^{-5} \mathrm{~m}$ & 50 & $80 \mathrm{~m}$ \\
\hline 30 & $10^{-4} \mathrm{~m}$ & 7 & $150 \mathrm{~m}$ & $90^{\circ}$ & $3.16 \times 10^{-5} \mathrm{~m}$ & 50 & $90 \mathrm{~m}$ \\
\hline 31 & $10^{-4} \mathrm{~m}$ & 7 & $150 \mathrm{~m}$ & $90^{\circ}$ & $3.16 \times 10^{-5} \mathrm{~m}$ & 50 & $110 \mathrm{~m}$ \\
\hline 32 & $10^{-4} \mathrm{~m}$ & 7 & $150 \mathrm{~m}$ & $90^{\circ}$ & $3.16 \times 10^{-5} \mathrm{~m}$ & 50 & $120 \mathrm{~m}$ \\
\hline
\end{tabular}

fracture angle. The detailed information about these 32 Cases are listed in Table 1.

\section{Model assumptions}

- The fluid is compressible methane gas.

- The seepage process is isothermal and single-phase.

- The seepage process meets the Darcy's law both in the rock matrix and fractures.

- Consider the effect of Knudsen diffusion in the rock matrix.
- Ignore the gas adsorption-desorption process.

- Gas flow into hydraulic and natural fractures and finally produced through the horizontal well. 


\section{Model establishment}

\section{Governing equation}

According to the conservation of mass equation, the gas flow in rock matrix can be described by the following equations (Mi et al. 2014)

$\rho S_{\mathrm{m}} \frac{\partial p}{\partial t}+\nabla \cdot(\rho u)=0$

where $\rho \mathrm{kg} / \mathrm{m}^{3}$ is the gas density, $S_{\mathrm{m}}(1 / \mathrm{Pa})$ is the matrix storage coefficient, $p(\mathrm{~Pa})$ is the pore pressure, $s$ is time and $u(\mathrm{~m} / \mathrm{s})$ is the gas flow velocity in matrix.

According to the corrected ideal gas state equation, the gas density $\rho$ can be written as

$\rho=\frac{M}{R T} \frac{p}{Z}$

where $M(\mathrm{~kg} / \mathrm{mol})$ is gas Molar mass, $R(8.314 \mathrm{~J} /(\mathrm{mol} \cdot \mathrm{K}))$ ,$T(\mathrm{~K})$ is the environmental temperature, $Z$ is gas compression factor.

The matrix storage coefficient $S_{\mathrm{m}}$ can be described as

$S_{\mathrm{m}}=C_{\mathrm{g}} \cdot \varphi+C_{\mathrm{m}}(1-\varphi)$

where $C_{\mathrm{g}}(1 / \mathrm{Pa})$ and $C_{\mathrm{m}}(1 / \mathrm{Pa})$ are the gas compression ratio and rock matrix compression ratio, respectively, $\varphi$ is the matrix porosity.

The gas compression ratio can be obtained by the following formula:

$C_{\mathrm{g}}=-\frac{1}{V}\left(\frac{\partial V}{\partial P}\right)=\frac{1}{P}-\frac{1}{Z}\left(\frac{\partial Z}{\partial P}\right)$

where $V\left(\mathrm{~m}^{3}\right)$ is the gas volume.

Consider the Darcy's law and Knudsen diffusion effect, the gas velocity in matrix can be expressed as (Cao et al. 2017)

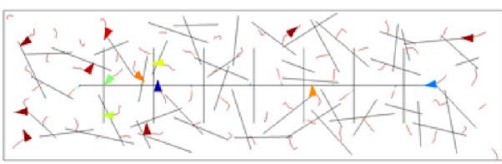

(a) $1 \mathrm{~d}$

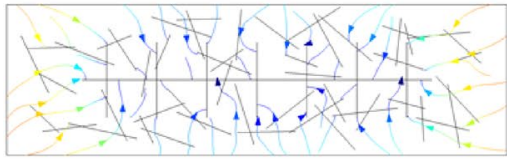

(d) $200 d$

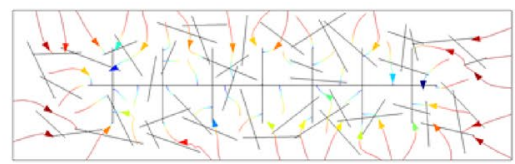

(b) $20 d$

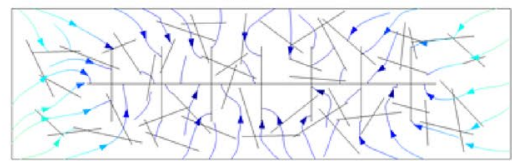

(e) $500 \mathrm{~d}$ $u=-\left(\frac{k_{\mathrm{m}}}{\mu}\right)+\frac{\varphi}{\tau} \frac{2 r}{3} \sqrt{\frac{8 R T}{\pi M}} \frac{1}{p} \nabla p$

where $k_{\mathrm{m}}\left(\mathrm{m}^{2}\right)$ is the rock matrix permeability, $\mu(\mathrm{Pa} \cdot \mathrm{s})$ is the gas viscosity, $\tau$ is the medium curvature and $r(\mathrm{~m})$ is the average pore radius.

According to the conservation of mass equation, the gas flow in fracture can be described by the following equations

$\rho S_{f} \omega \frac{\partial p}{\partial t}+\nabla \cdot\left(\rho u_{f}\right)=0$

$u_{f}=-\frac{k_{f}}{\mu} \omega \nabla p$

where $S_{f}(1 / \mathrm{Pa})$ is the fracture storage coefficient, $\omega(\mathrm{m})$ is the fracture aperture, $u_{f}(\mathrm{~m} / \mathrm{s})$ is the gas flow velocity in fracture and $k_{f}\left(\mathrm{~m}^{2}\right)$ is the fracture permeability.

In this paper, the fracture permeability is calculated by the cubic law, which can be expressed by

$k_{f}=\frac{\omega^{2}}{12}$

\section{Initial and boundary conditions}

The initial pressure and temperature of reservoir are $5 \mathrm{MPa}$ and $293.15 \mathrm{~K}$, respectively. In the whole simulation, the bottom hole pressure of horizontal well always maintain $0.1 \mathrm{MPa}$. Set the periphery of the model to zero flow boundary.

\section{Results and discussion}

\section{Analysis of seepage field}

In this section, we investigated the velocity distribution and pressure distribution of Case 1. Figure 2 illustrates the flow

Fig. 2 Velocity field distribution of Case 1 


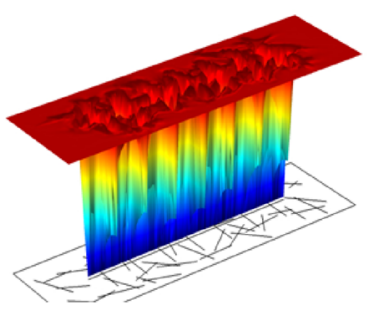

(a) $1 \mathrm{~d}$

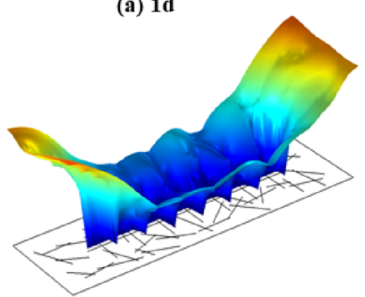

(d) 200d

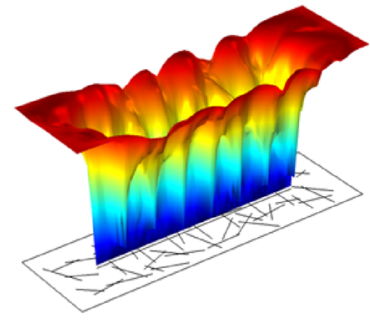

(b) $20 d$

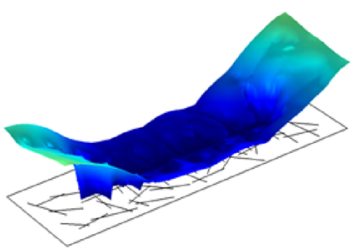

(e) $500 \mathrm{~d}$

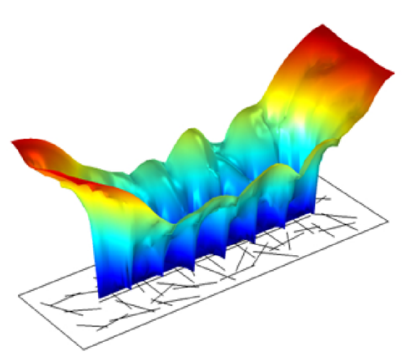

(c) $100 d$

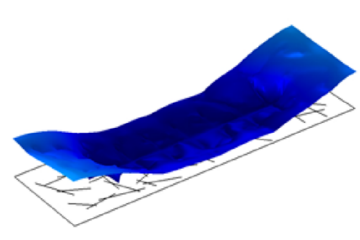

(f) $1000 \mathrm{~d}$

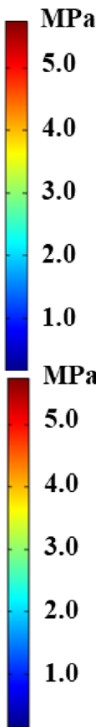

Fig. 3 Pressure field distribution of Case 1

line distribution of shale gas reservoir at $1 \mathrm{~d}, 20 \mathrm{~d}, 100 \mathrm{~d}$, $200 \mathrm{~d}, 500 \mathrm{~d}$ and $1000 \mathrm{~d}$, the flow lines are evenly distributed and the direction and color of the arrows represent the fluid flow direction and pressure value, respectively. It can be observed that the fluid flow into the horizontal well is mainly divided into two ways: from natural fractures to the hydraulic fractures and then into the horizontal well; from natural fractures or hydraulic fractures into the horizontal well. It means that fractures are key flow channel for the fluid and the fracture properties are bound to have a critical impact on the exploitation of shale gas.

Figure 3 demonstrates the pressure distribution of shale gas reservoir at $1 \mathrm{~d}, 20 \mathrm{~d}, 100 \mathrm{~d}, 200 \mathrm{~d}, 500 \mathrm{~d}$ and $1000 \mathrm{~d}$, the color legend represents the pressure value. It can be seen from Fig. 3 that the shale gas development process leads to the expand of low-pressure region and the expand phenomenon becomes more and more obvious with time. Besides, the nonuniformity of the fracture distribution determines the nonuniformity of the pressure field diffusion. The pressure propagates rapidly in areas with denser fractures.

In order to observe the pressure variation of shale gas reservoir more clearly and intuitively, the two-dimensional cut lines $\mathrm{AB}, \mathrm{CD}$ and $\mathrm{EF}$ are taken in the model (as shown in Fig. 4.). The pressures in the horizontal well, hydraulic fractures and natural fractures are demonstrated in Fig. 5. It can be concluded from Fig. 5a that the horizontal well pressure always maintains constant and the pressure of horizontal well extension line decreases with time and the decrease rate gradually slows down. We can see that from Fig. $5 b$ that the pressure of hydraulic fracture is always lower than that of the matrix. The pressure of hydraulic fracture is about $1 / 3$ of the matrix at $1 \mathrm{~d}$ and $1 / 5$ of the matrix at $500 \mathrm{~d}$. It can be seen from Fig. $5 \mathrm{c}$ that the pressure fluctuation mainly occurs at the fractures. Due to the permeability of hydraulic fractures is higher than that of natural fractures, the pressure fluctuation at the hydraulic fracture is always higher than that at natural fracture.
Fig. 4 Schematic diagram with two-dimensional cut lines of Case 1

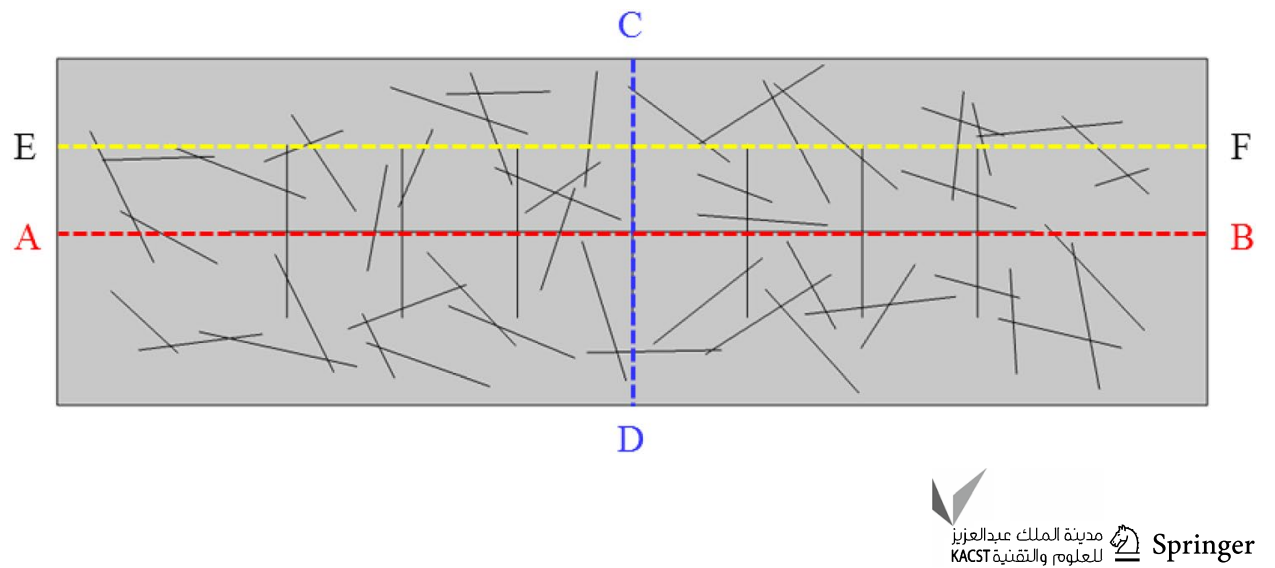



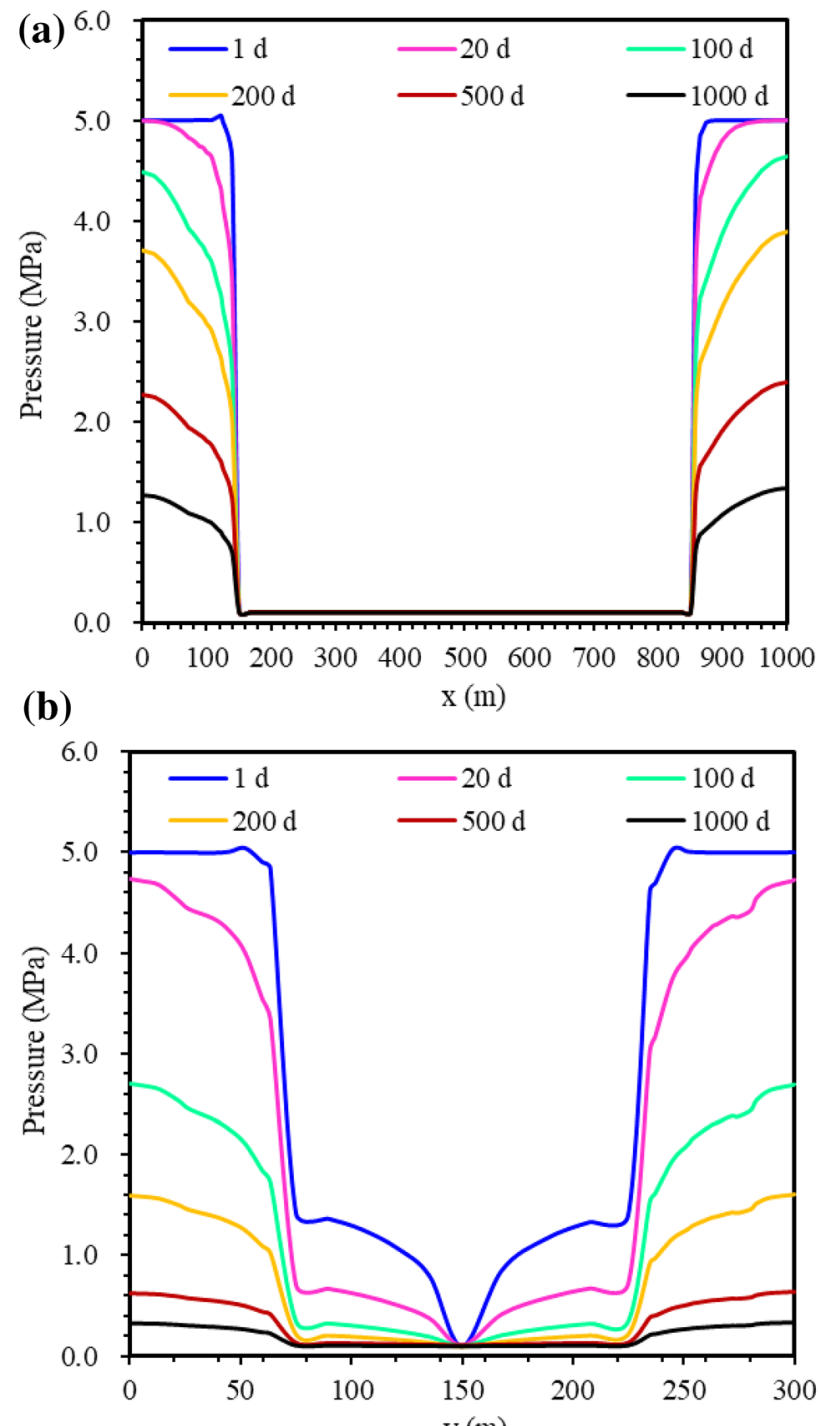

(c)

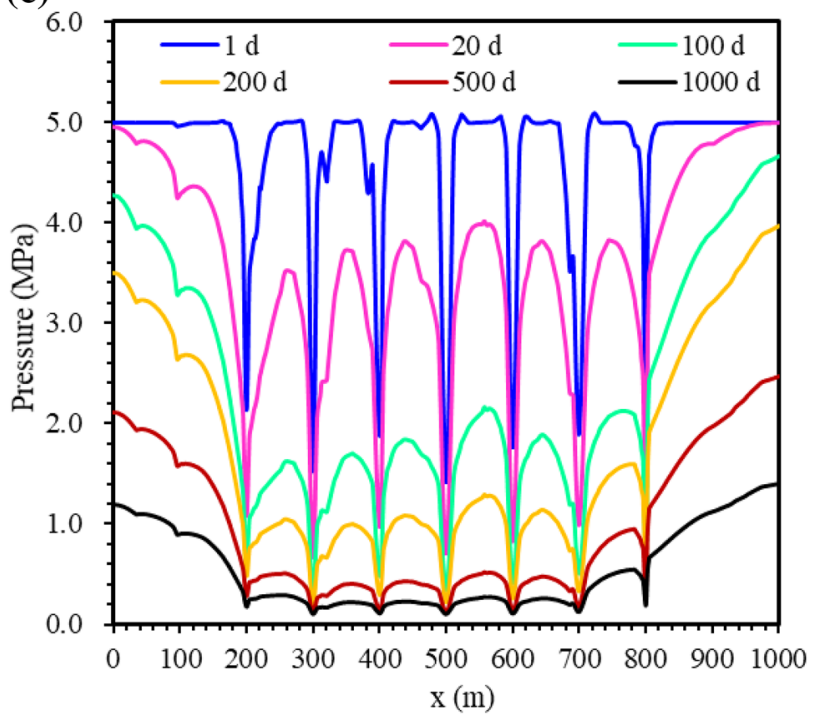

Fig. 5 a Pressure variation at $\mathrm{AB}$ of Case 1. b Pressure variation at $\mathrm{CD}$ of Case 1.c Pressure variation at EF of Case 1

\section{Effect of hydraulic fracture geometries}

In fractured shale gas reservoir, there is optimal fracture geometry for shale gas development. In this part, four parameters including aperture, number, length and inclination angle of hydraulic fracture are compared. In order to investigate the fracture geometry on shale gas production and select the best fractures distribution forms.

\section{Hydraulic fracture aperture}

In this section, the effect of hydraulic fracture aperture on shale gas development was investigated based on Case 2-6. It can be speculated from Fig. 6 that the hydraulic fracture is the key factor in shale gas development from the pressure distribution difference in Fig. 6. Figure 7 demonstrates the production rate and cumulative production variation with time under various hydraulic fracture aperture, respectively. It can be seen that the production rate increase with the rise of the hydraulic fracture aperture. This is because the variation of hydraulic fracture aperture affects the fracture permeability and seepage flow. It is found that that as the hydraulic fracture aperture rises, the cumulative production increases. When the hydraulic fracture aperture is $10^{-4} \mathrm{~m}, 10^{-5} \mathrm{~m}$, $10^{-6} \mathrm{~m}$ at $500 \mathrm{~d}$, the cumulative production is $4.44 \times 10^{6} \mathrm{~m}^{3}$, $5.33 \times 10^{5} \mathrm{~m}^{3}, 1.23 \times 10^{4} \mathrm{~m}^{3}$, respectively. Compared with the hydraulic fracture aperture of $10^{-4} \mathrm{~m}$, when the aperture is $10^{-5} \mathrm{~m}$ and $10^{-6} \mathrm{~m}$, the cumulative production is reduced by $88.0 \%$ and $99.7 \%$, respectively. Under the research conditions, the optimal value of hydraulic fracture aperture is $10^{-4} \mathrm{~m}$.

\section{Number of hydraulic fractures}

In this section, the effect of number of hydraulic fractures on shale gas development was studied based on Case 1, 7-12. The pressure distribution varies with the number of hydraulic fractures as shown in Fig. 8, thus affecting the production of shale gas. It can be found from Fig. 9 that the production rate and cumulative production increase with the rise of number of hydraulic fractures. When the number of hydraulic fractures is $4,5,6,7,8,9,10$ at $500 \mathrm{~d}$, the cumulative production is $6.81 \times 10^{6} \mathrm{~m}^{3}, 7.40 \times 10^{6} \mathrm{~m}^{3}, 7.77 \times 10^{6}$ $\mathrm{m}^{3}, 7.94 \times 10^{6} \mathrm{~m}^{3}, 8.06 \times 10^{6} \mathrm{~m}^{3}, 8.16 \times 10^{6} \mathrm{~m}^{3}, 8.43 \times 10^{6}$ $\mathrm{m}^{3}$, respectively. For each additional fracture, the cumulative production of the latter increased by $8.7 \%, 5.0 \%, 2.2 \%, 1.5 \%$, $1.2 \%$ than the former, respectively. It can be observed that the growth of cumulative production decreases with the rise of number of hydraulic fractures. It demonstrates that the increase in number of hydraulic fractures provides more flow channels for shale gas, allowing more fluid to flow through the fractures to the horizontal wells, thus, the cumulative production is improved. However, due to limited shale gas 
Fig. 6 Pressure distribution under various hydraulic fracture aperture at $500 \mathrm{~d}$

Fig. 7 Production rate and cumulative production variation under various hydraulic fracture aperture

Fig. 8 Pressure distribution under various number of hydraulic fractures at $500 \mathrm{~d}$

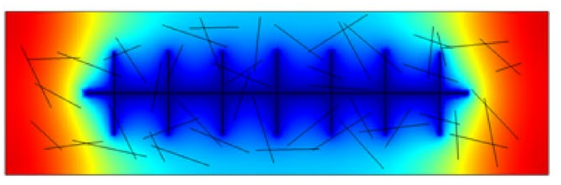

(a) Case 2

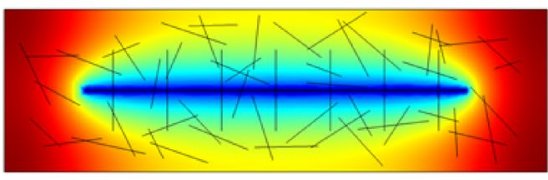

(c) Case 4

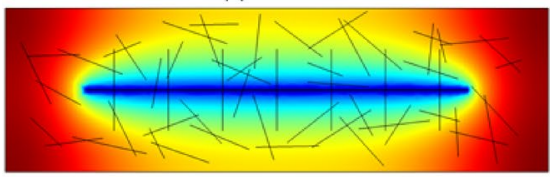

(e) Case 6

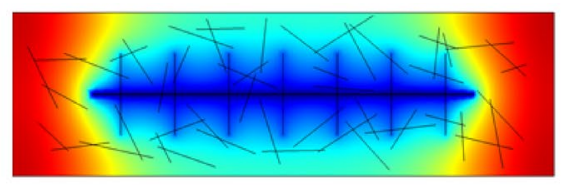

(b) Case 3

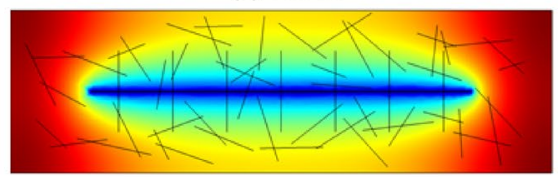

(d) Case 5

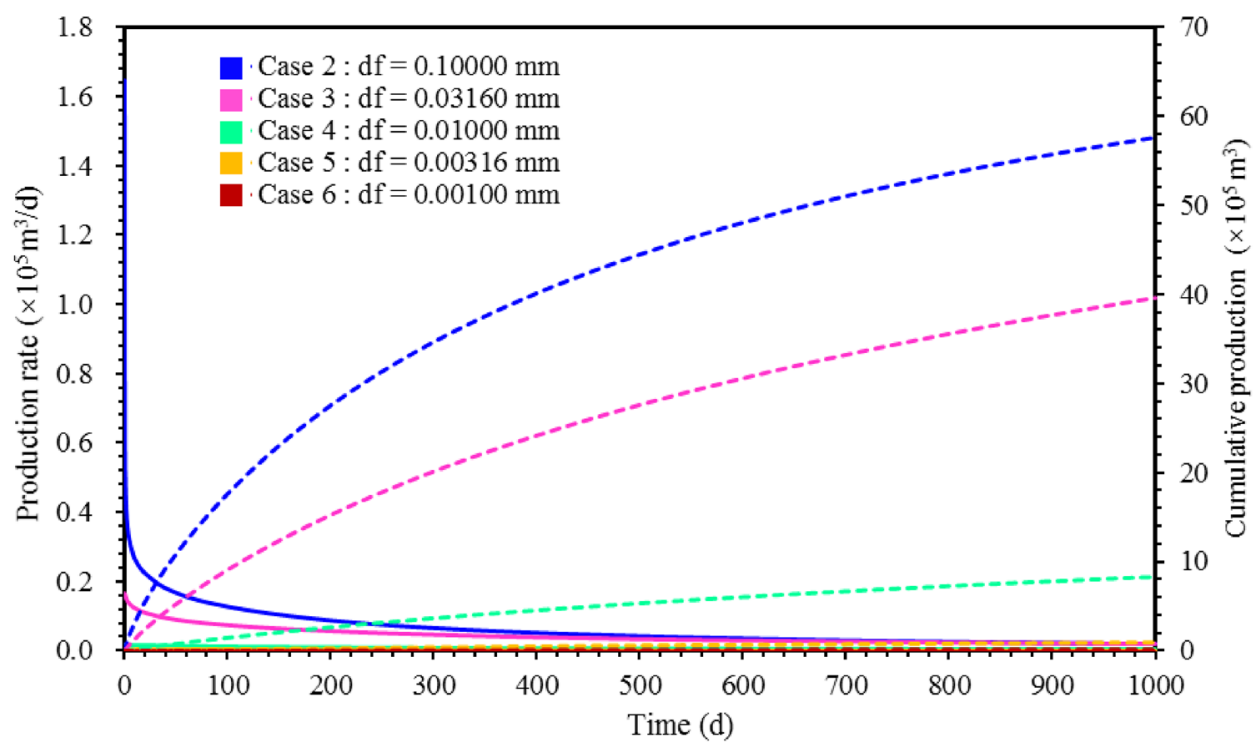

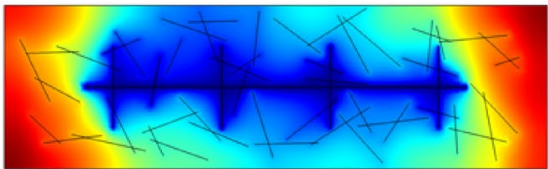

(a) Case 7

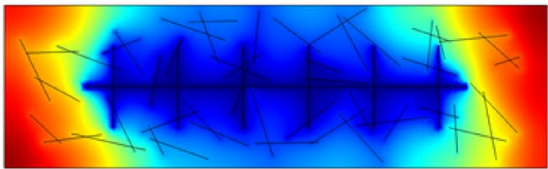

(c) Case 9

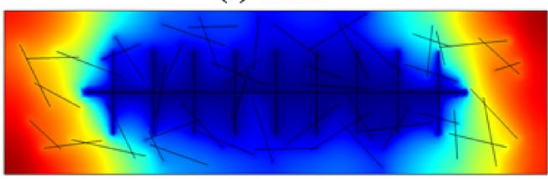

(e) Case 11

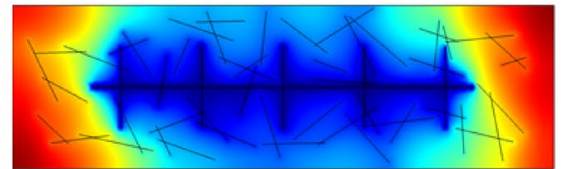

(b) Case 8

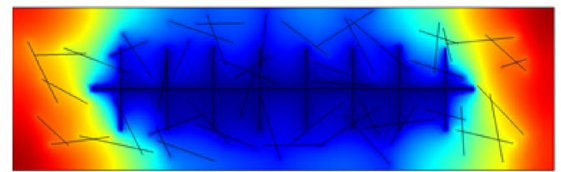

(d) Case 10

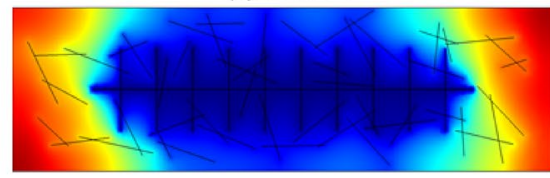

(f) Case 12 
Fig. 9 Production rate and cumulative production variation under various number of hydraulic fractures

Fig. 10 Pressure distribution under various hydraulic fracture length at $500 \mathrm{~d}$

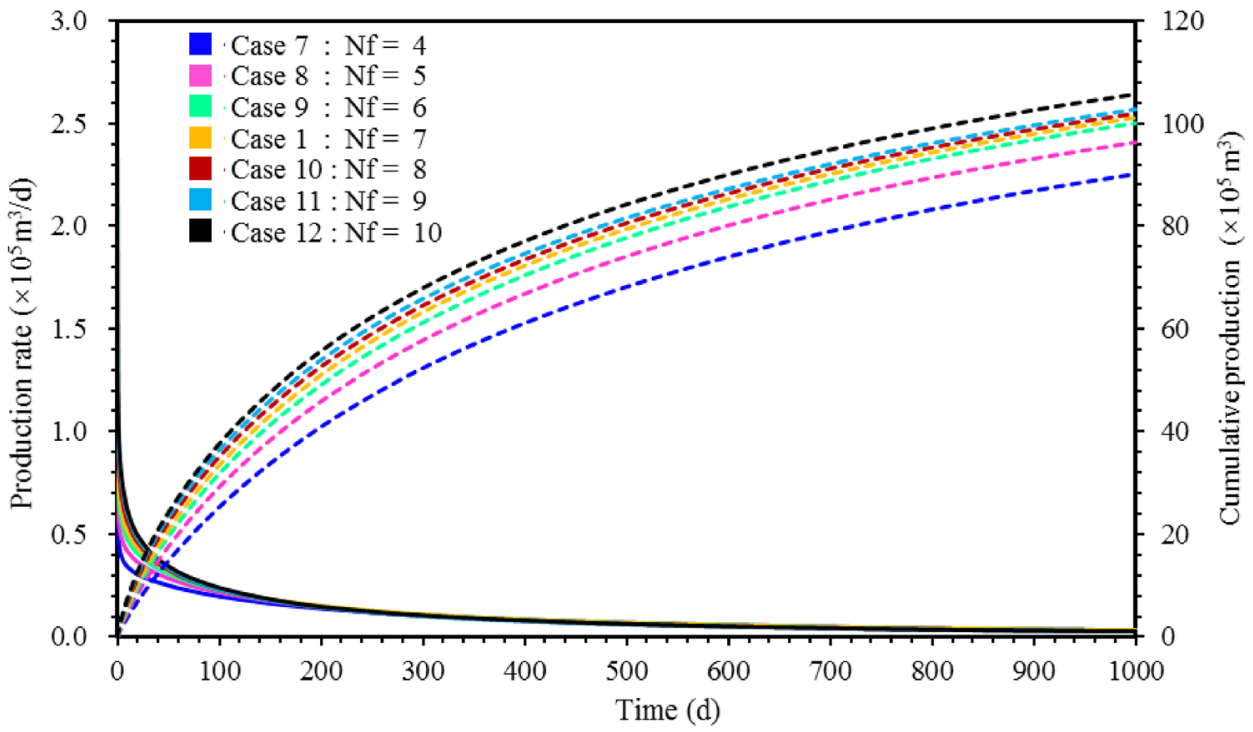

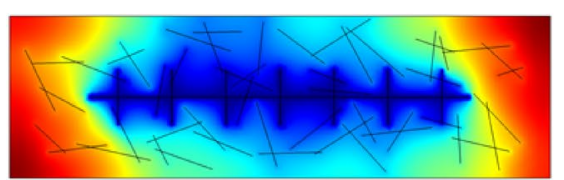

(a) Case 13

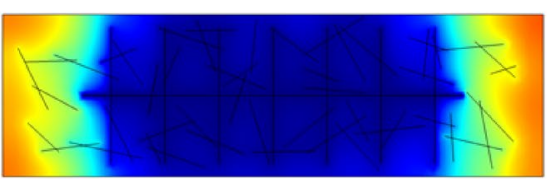

(c) Case 15

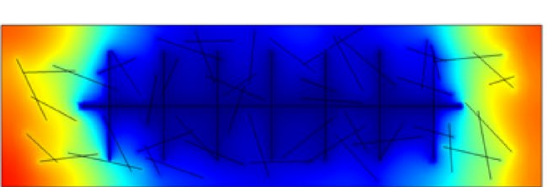

(b) Case 14

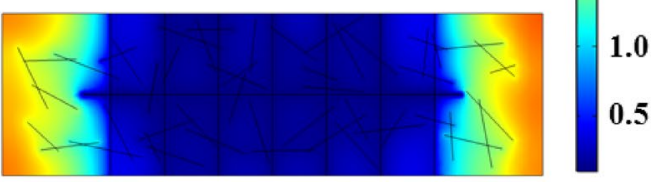

(d) Case 16

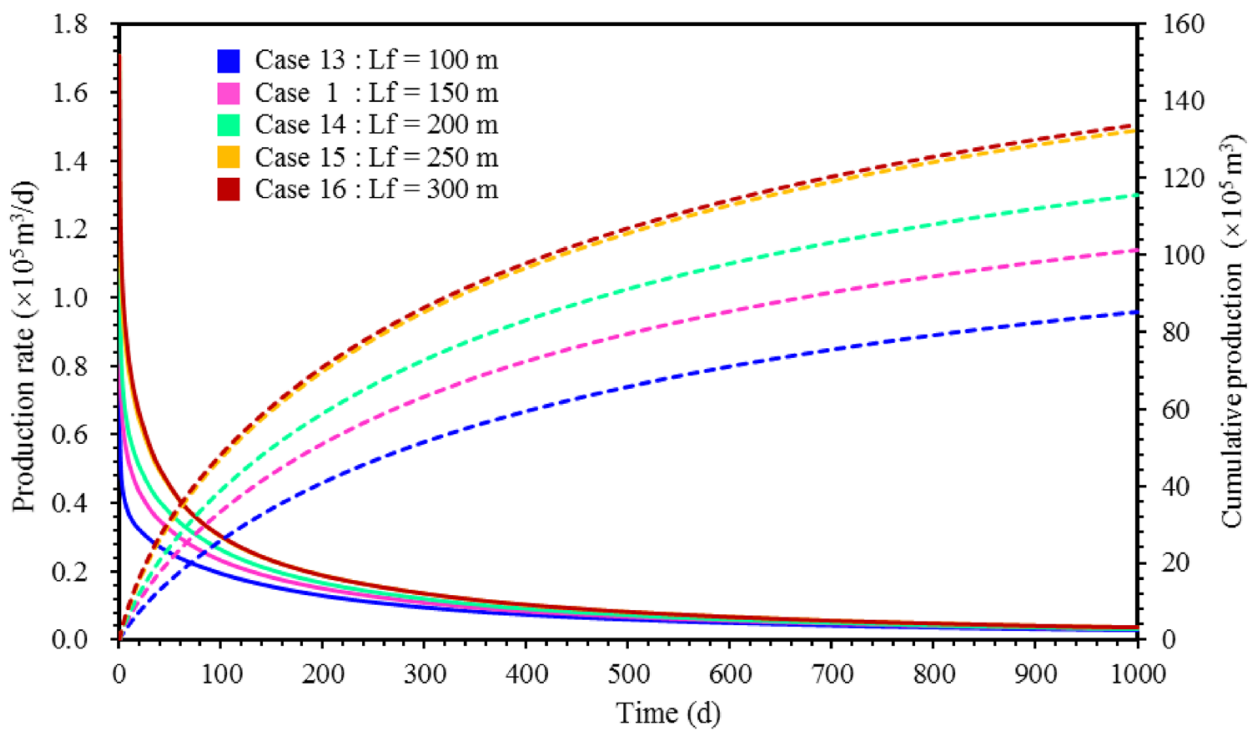

Fig. 11 Production rate and cumulative production variation under various hydraulic fracture length 
reserves, when the number of hydraulic fractures increases to a certain value, the growth of cumulative production is no longer obvious. Under the research conditions, the optimal number of hydraulic fractures is 10 .

\section{Hydraulic fracture length}

In this section, the effect of hydraulic fracture length on shale gas development was studied based on Case 1, 13-16. It can be seen from Fig. 10 that the hydraulic fracture length has an important influence on the region and velocity of pressure drop. From Fig. 11. it can be found that the production rate and cumulative production increase with the rise of hydraulic fracture length. When the hydraulic fracture length is $100 \mathrm{~m}, 150 \mathrm{~m}, 200 \mathrm{~m}, 250 \mathrm{~m}, 300 \mathrm{~m}$ at $500 \mathrm{~d}$, the cumulative production is $6.59 \times 10^{6} \mathrm{~m}^{3}, 7.94 \times 10^{6} \mathrm{~m}^{3}, 9.11 \times 10^{6}$ $\mathrm{m}^{3}, 1.06 \times 10^{7} \mathrm{~m}^{3}, 1.07 \times 10^{7} \mathrm{~m}^{3}$, respectively. When the hydraulic fracture length increases from 100 to $300 \mathrm{~m}$, the fractures contact the further area of matrix, which enlarges the area of permeability improvement of shale reservoir and increases the cumulative production of shale gas. Compared with the hydraulic fracture length is $100 \mathrm{~m}$, when the length is $200 \mathrm{~m}$ and $300 \mathrm{~m}$, the cumulative production is increased by $38.2 \%$ and $62.4 \%$, respectively. Under the research conditions, the optimal value of hydraulic fracture aperture is $10^{-4} \mathrm{~m}$.

\section{Hydraulic fracture angle}

In this section, the effect of hydraulic fracture angle on shale gas development is studied based on Case 1,17-20. It can be found from Fig. 12 that the hydraulic fracture angle is the key factor on the region and velocity of pressure drop. In Fig. 13, it can be observed that from that the production rate and cumulative production increase with the reduction of hydraulic fracture angle. When the hydraulic fracture angle is $90^{\circ}, 75^{\circ}, 60^{\circ}, 45^{\circ}, 30^{\circ}$ at $500 \mathrm{~d}$, the cumulative production is $7.94 \times 10^{6} \mathrm{~m}^{3}, 8.00 \times 10^{6} \mathrm{~m}^{3}, 8.21 \times 10^{6} \mathrm{~m}^{3}, 8.51 \times 10^{7}$ $\mathrm{m}^{3}, 8.85 \times 10^{7} \mathrm{~m}^{3}$, respectively. It can be speculated that the reduction in the hydraulic fracture angle changes its relative position with the horizontal well. The smaller the angle is, the more favorable for fluid flow into fractures then
Fig. 12 Pressure distribution under various hydraulic fracture angle at $500 \mathrm{~d}$

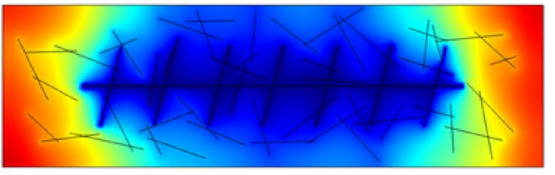

(a) Case 17

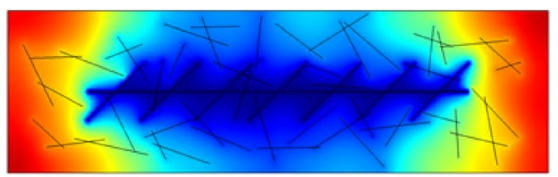

(c) Case 19

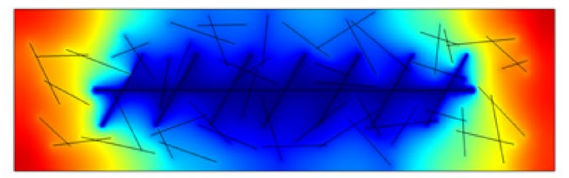

(b) Case 18

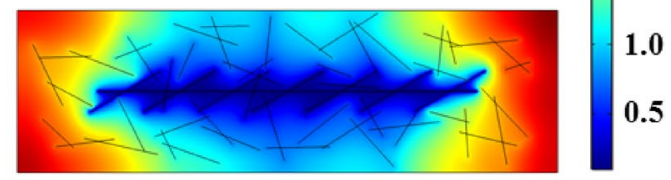

(d) Case 20 2.5 2.0 1.5 .0 0.5

MPa

Fig. 13 Production rate and cumulative production variation under various hydraulic fracture angle

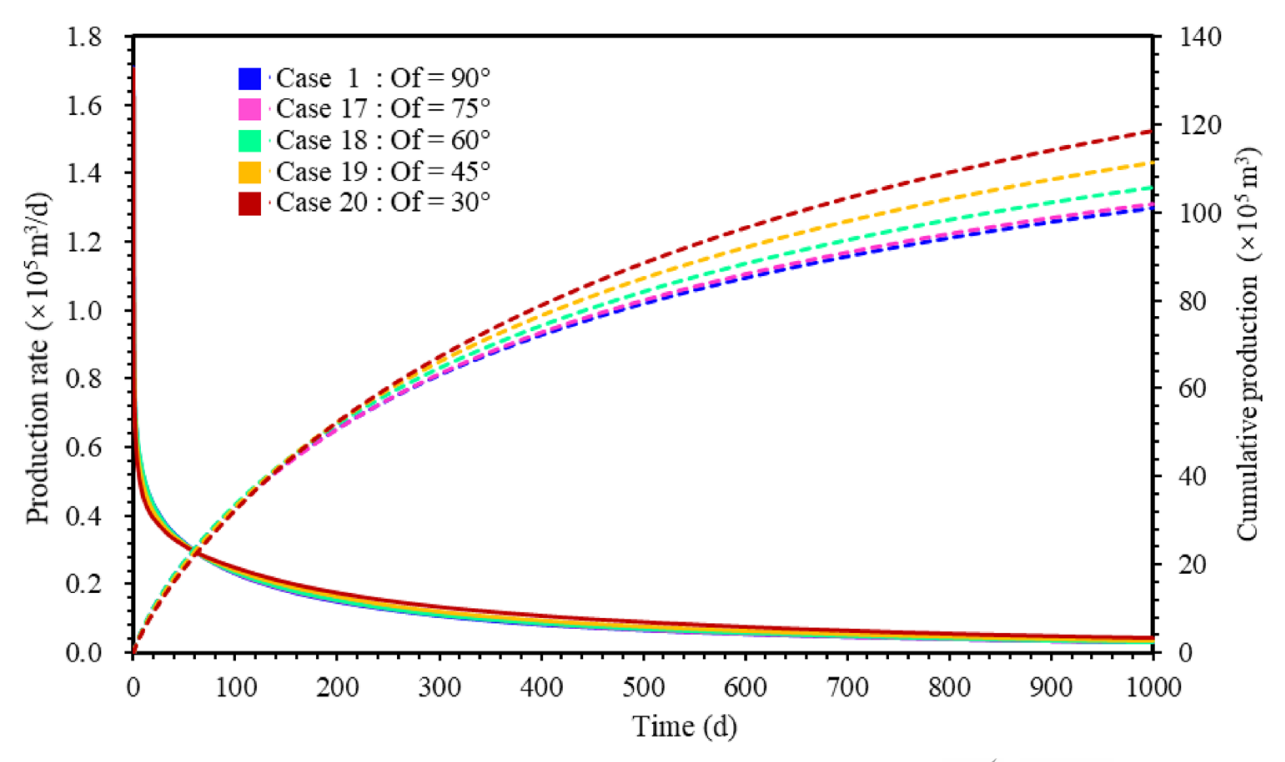


into the horizontal well, thereby increasing the cumulative production.

Fig. 14 Pressure distribution under various natural fracture aperture at $500 \mathrm{~d}$

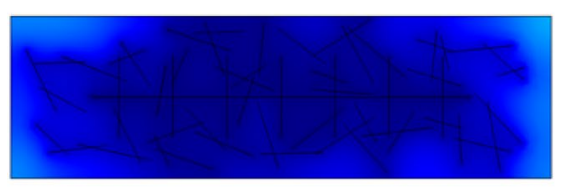

(a) Case 21

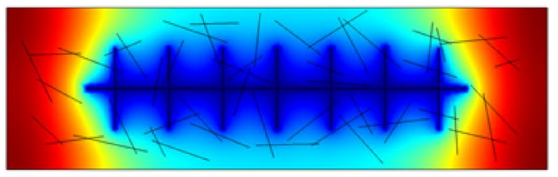

(c) Case 23

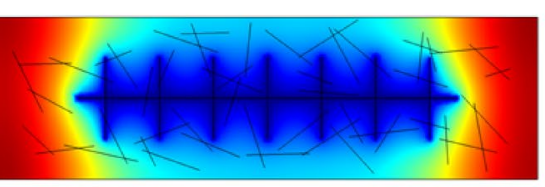

(b) Case 22

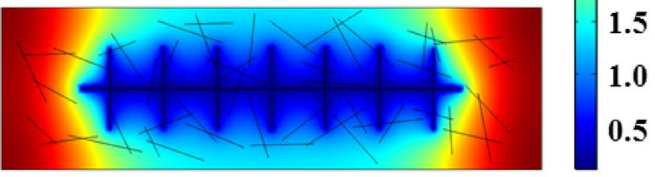

(d) Case 24
Fig. 15 Production rate and cumulative production variation under various natural fracture aperture
Fig. 16 Pressure distribution under various number of natural fractures at $500 \mathrm{~d}$

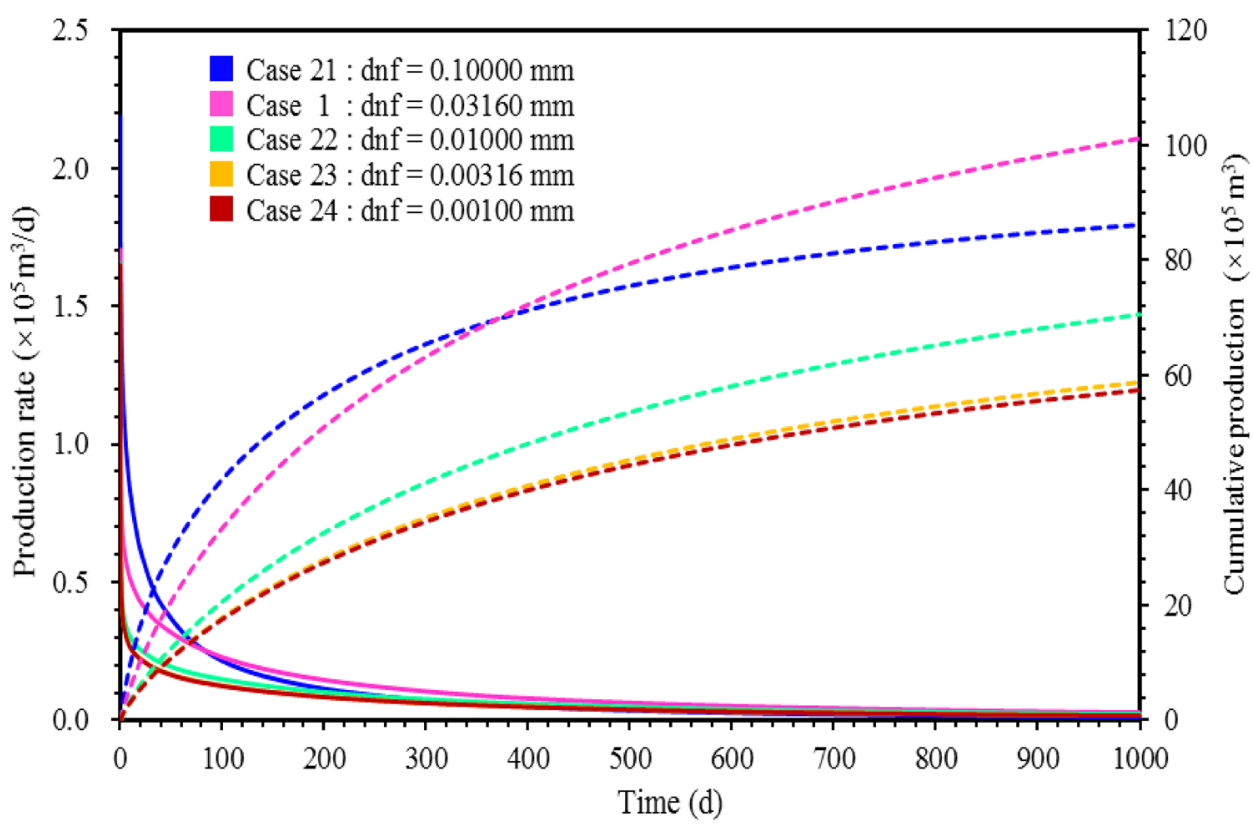

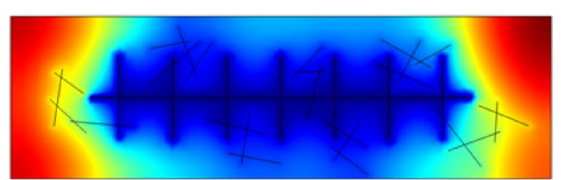

(a) Case 25

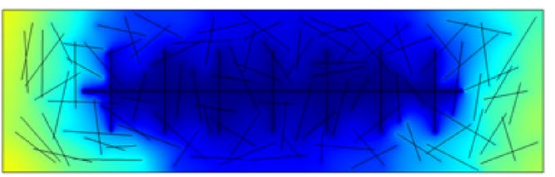

(c) Case 27

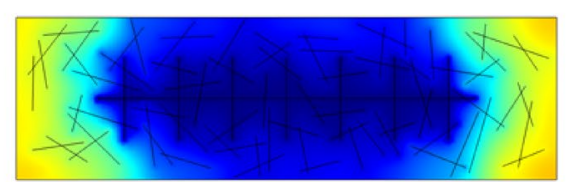

(b) Case 26

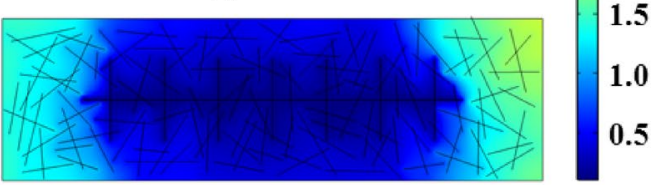

(d) Case 28 5 
Figure 14 illustrates the pressure distribution under various natural fracture aperture at $500 \mathrm{~d}$. It can be speculated that the natural fracture aperture has a certain influence on the pressure distribution. Figure 15 demonstrates the production rate and cumulative production variation with time under various natural fracture aperture, respectively. It can be seen that when the natural fracture aperture is $3.16 \times 10^{-5} \mathrm{~m}$, $10^{-5} \mathrm{~m}, 3.16 \times 10^{-6} \mathrm{~m}$ and $10^{-6} \mathrm{~m}$, the production rate and cumulative production increase with the rise of the natural fracture aperture. When the natural fracture aperture is $10^{-4} \mathrm{~m}$ which is equal to the hydraulic fracture aperture, the production rate and cumulative production decrease in the late development period compared with the natural fracture aperture is $3.16 \times 10^{-5} \mathrm{~m}$. This is because that when the hydraulic fracture permeability and natural fracture permeability are the same, the overall permeability of fractures is high which leads to rapid reservoir pressure drops. Therefore, the shale gas production rate and cumulative production decrease in the late development period.

\section{Number of natural fractures}

In this section, the effect of number of natural fractures on shale gas development is studied based on Case 1, 25-28. From Fig. 16, it can be observed that pressure distribution varies with the number of natural fractures, thus affecting the production of shale gas. It can be found from Fig. 17 that the production rate and cumulative production increase with the rise of number of fractures. When the number of natural fractures is $25,50,75,100,125$ for $500 \mathrm{~d}$, the cumulative production is $6.42 \times 10^{6} \mathrm{~m}^{3}, 7.94 \times 10^{6} \mathrm{~m}^{3}, 8.71 \times 10^{6}$ $\mathrm{m}^{3}, 9.29 \times 10^{7} \mathrm{~m}^{3}, 9.68 \times 10^{7} \mathrm{~m}^{3}$, respectively. For each 25 additional natural fracture, the cumulative production of the latter increased by $23.7 \%, 9.7 \%, 6.7 \%, 4.2 \%$ than the former, respectively. The growth of cumulative production decreases with the rise of number of natural fractures. It can be speculated that due to limited shale gas reserves, when the number of natural fractures increases to a certain value, the growth of cumulative production is no longer obvious. The effect number of natural fractures has the similar results on shale gas production with hydraulic fractures.
Fig. 17 Production rate and cumulative production variation under various number of natural fractures
Fig. 18 Pressure distribution under various natural fracture length at $500 \mathrm{~d}$

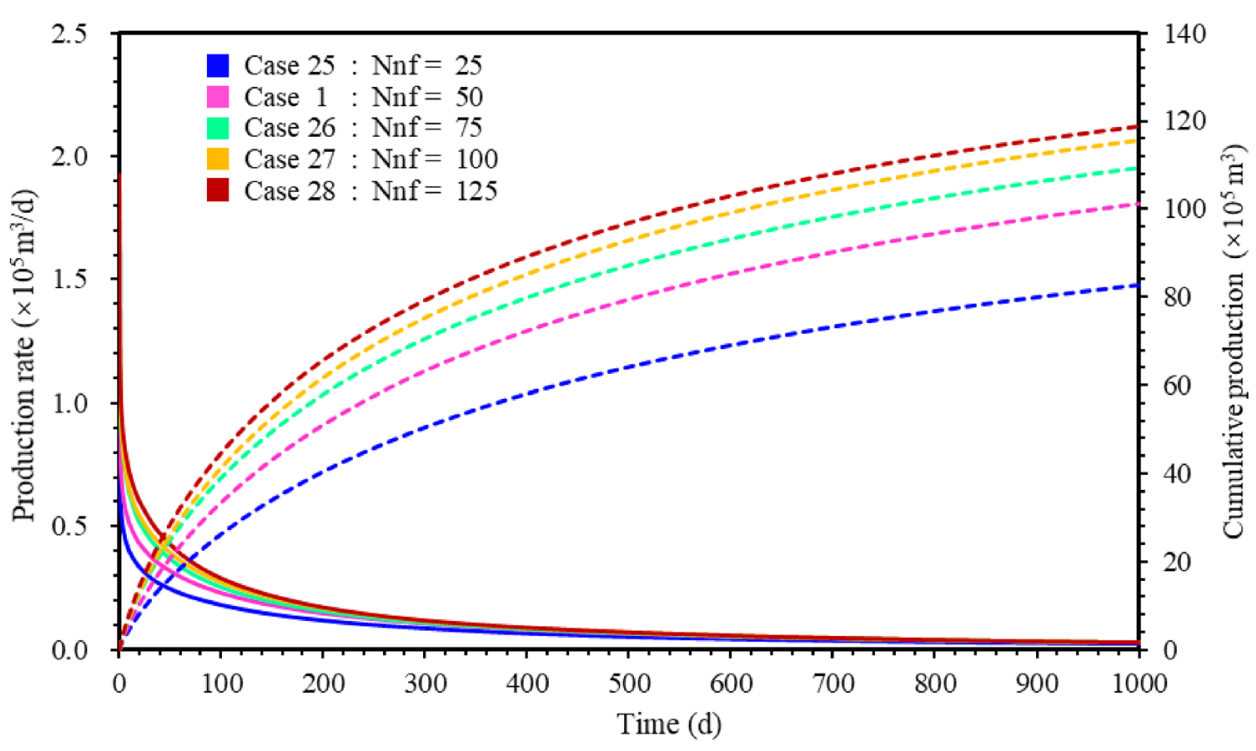

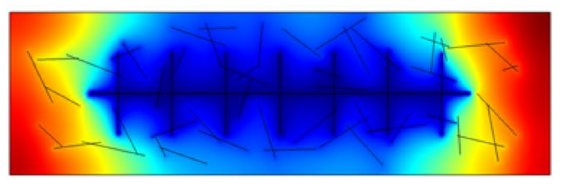

(a) Case 28

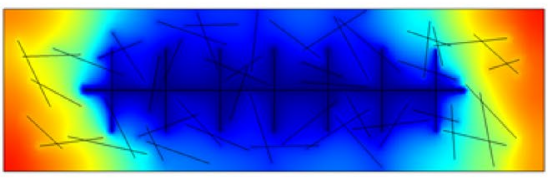

(c) Case 30

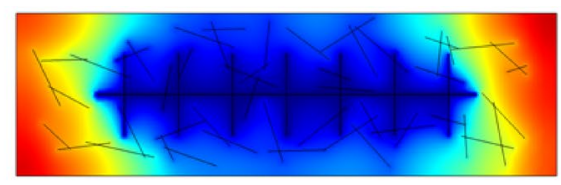

(b) Case 29

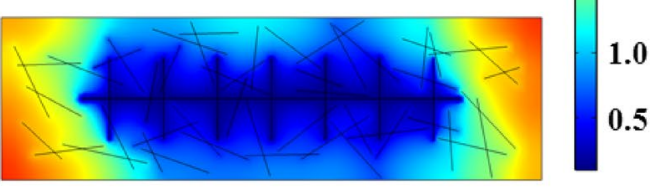

(d) Case 31

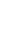


Fig. 19 Production rate and cumulative production variation under various natural fracture length

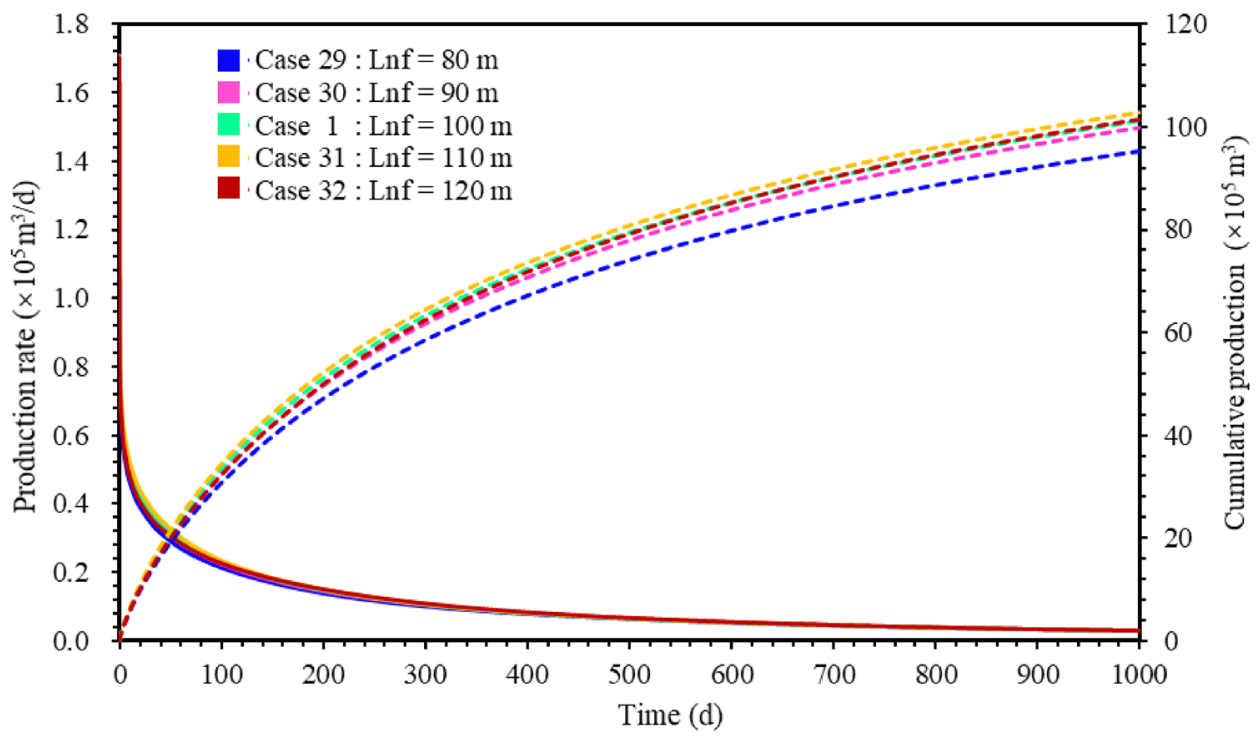

\section{Natural fracture length}

In this section, the effect of natural fracture length on shale gas development is studied based on Case 1, 29-32. Compared with the influence of hydraulic fracture length on pressure distribution, the influence of natural fracture length on pressure distribution is relatively small as shown in Fig. 18. It can be observed from Fig. 19. that the production rate and cumulative production increase with the rise of natural fracture length when the natural fracture length ranges from 80 to $110 \mathrm{~m}$. When the natural fracture length reaches to $120 \mathrm{~m}$, the cumulative production decreases slightly. When the natural fracture length is $80 \mathrm{~m}, 90 \mathrm{~m}, 100 \mathrm{~m}, 110 \mathrm{~m}$, $120 \mathrm{~m}$ for $500 \mathrm{~d}$, the cumulative production is $7.40 \times 10^{6}$ $\mathrm{m}^{3}, 7.79 \times 10^{6} \mathrm{~m}^{3}, 7.94 \times 10^{6} \mathrm{~m}^{3}, 8.09 \times 10^{7} \mathrm{~m}^{3}, 7.93 \times 10^{7}$ $\mathrm{m}^{3}$, respectively. When the natural fracture length increases from 80 to $120 \mathrm{~m}$, the fractures contact the further area of matrix so as to enlarge the area of permeability improvement of shale reservoir, thus increases the cumulative production of shale gas. Compared with the natural fracture length is $80 \mathrm{~m}$, when the length is $90 \mathrm{~m}, 100 \mathrm{~m}, 110 \mathrm{~m}, 120 \mathrm{~m}$, the cumulative production is increased by $5.3 \%, 7.3 \%, 9.3 \%$ and $7.2 \%$, respectively.

\section{Conclusions}

1. The shale gas reservoir is regarded as a dual medium consisting of fracture (hydraulic fracture and discrete natural fracture network) and rock matrix, the seepage process in the fracture and rock matrix is fully considered and a mathematical model of seepage flow in accordance with Darcy's law was established.
2. From the perspective of the cumulative output variation, the influence of hydraulic fracture geometry on the cumulative production has been investigated. Hydraulic fracture aperture and length play a leading role in the variation of cumulative production. The increase in the hydraulic fracture aperture increases the fracture permeability, which make it more conducive to gas flow into the fracture, thereby increasing the cumulative production. Compared with the hydraulic fracture aperture of $10^{-4} \mathrm{~m}$, when the aperture is $10^{-5} \mathrm{~m}$ and $10^{-6} \mathrm{~m}$, the cumulative production is reduced by $88.0 \%$ and $99.7 \%$, respectively. The increase in the hydraulic fracture length makes it connect more natural fractures, the connectivity of the shale reservoir becomes better and the cumulative production increases more. Compared with the hydraulic fracture length is $100 \mathrm{~m}$, when the length is $200 \mathrm{~m}$ and $300 \mathrm{~m}$, the cumulative production is increased by $38.2 \%$ and $62.4 \%$, respectively.

3 . From the perspective of the cumulative output variation, the influence order of natural fracture geometry on the cumulative production has been studied. Natural fracture aperture and number play a leading role in the variation of cumulative production. The increase in the natural fracture aperture increases the fracture permeability, which make it more conducive to gas flow into the fracture, thereby increasing the cumulative production. The increase in the number of natural fractures makes the connectivity of the shale reservoir becomes better and the cumulative production increases more. When the number of natural fractures is $25,50,75,100,125$ for $500 \mathrm{~d}$, the cumulative production is $6.42 \times 10^{6} \mathrm{~m}^{3}$, $7.94 \times 10^{6} \mathrm{~m}^{3}, 8.71 \times 10^{6} \mathrm{~m}^{3}, 9.29 \times 10^{7} \mathrm{~m}^{3}, 9.68 \times 10^{7}$ $\mathrm{m}^{3}$, respectively. For each 25 additional natural fracture, 
the cumulative production of the latter increased by $23.7 \%, 9.7 \%, 6.7 \%, 4.2 \%$ than the former, respectively.

\begin{abstract}
Acknowledgements The authors would like to acknowledge the financial support of the projection from National Natural Science Foundation of China. We would also like to express our gratitude to the editors and reviewers for their careful review of this manuscript.
\end{abstract}

Funding This study was supported by the National Natural Science Foundation of China (Grant No. 51474070).

Data availability The simulation data used to support the findings of this study are available from the corresponding author upon request.

\section{Compliance with ethical standards}

Conflict of interest No potential conflict of interest was reported by the authors.

Open Access This article is licensed under a Creative Commons Attribution 4.0 International License, which permits use, sharing, adaptation, distribution and reproduction in any medium or format, as long as you give appropriate credit to the original author(s) and the source, provide a link to the Creative Commons licence, and indicate if changes were made. The images or other third party material in this article are included in the article's Creative Commons licence, unless indicated otherwise in a credit line to the material. If material is not included in the article's Creative Commons licence and your intended use is not permitted by statutory regulation or exceeds the permitted use, you will need to obtain permission directly from the copyright holder. To view a copy of this licence, visit http://creativecommons.org/licenses/by/4.0/.

\section{References}

Cao P, Liu JS, Leong YK (2016) A fully coupled multiscale shale deformation-gas transport model for the evaluation of shale gas extraction. Fuel 178:103-117

Cao C, Zhao QP, Gao C, Sun JB, Xu J, Zhang P, Zhang L (2017) Discrete fracture model with multi-field coupling transport for shale gas reservoirs. J Petrol Sci Eng 158:107-119

Dai C, Liu H, Wang YY, Li X, Wang WH (2019) A simulation approach for shale gas development in China with embedded discrete fracture modeling. Mar Pet Geol 100:519-529

Fan X, Li GS, Shah SN, Tian SC, Sheng M, Geng LD (2015) Analysis of a fully coupled gas flow and deformation process in fractured shale gas reservoirs. J Natural Gas Sci Eng 27:901-913

Kudapa VK, Sharma P, Kunal V, Gupta DK (2017) Modeling and simulation of gas flow behavior in shale reservoirs. J Petrol Exploration Prod Technol 7:1095-1112

Li LK, Jiang HQ, Li JJ, Wu KL, Meng F, Xu QL, Chen ZX (2018) An analysis of stochastic discrete fracture networks on shale gas recovery. J Petrol Sci Eng 167:78-87

Liu C, Liu H, Zhang YP, Deng DW, Wu HA (2015) Optimal spacing of staged fracturing in horizontal shale-gas well. J Petrol Sci Eng 132:86-93

Ma YY, Li SB, Zhang LZ, Liu SZ, Liu ZY, Li H, Shi EX, Liu XM, Liu HL (2020a) Analysis on the heat extraction performance of multi-well injection enhanced geothermal system based on leaflike bifurcated fracture networks. Energy 213:118990

Ma YY, Li SB, Zhang LZ, Liu SZ, Liu ZY, Li H, Shi EX, Zhang HJ (2020b) Numerical simulation study on the heat extraction performance of multi-well injection enhanced geothermal system. Renew Energy 151:782-795

Ma YY, Li SB, Zhang LZ, Liu SZ, Liu ZY, Li H, Shi EX (2020c) Study on the effect of well layout schemes and fracture parameters on the heat extraction performance of enhanced geothermal system in fractured reservoir. Energy 202:117811

Mahmoud M, Aleid A, Ali A, Kamal MS (2020) An integrated workflow to perform reservoir and completion parametric study on a shale gas reservoir. J Petrol Exploration Prod Technol 10:1497-1510

Mi LD, Jiang HQ, Li JJ, Li T, Tian Y (2014) The investigation of fracture aperture effect on shale gas transport using discrete fracture model. J Natural Gas Sci Eng 21:631-635

Shar AM, Mahesar AA, Memon KR (2018) Could shale gas meet energy deficit: its current status and future prospects. J Petrol Exploration Prod Technol 8:957-967

Sun H, Yao J, Gao SH, Fan DY, Wang CC, Sun ZX (2013) Numerical study of $\mathrm{CO}_{2}$ enhanced natural gas recovery and sequestration in shale gas reservoirs. Int J Greenhouse Gas Control 19:406-419

Wang HY (2018) Discrete fracture networks modeling of shale gas production and revisit rate transient analysis in heterogeneous fractured reservoirs. J Petrol Sci Eng 169:796-812

Wei SM, Xia Y, Jin Y, Chen M, Chen KP (2019) Quantitative study in shale gas behaviors using a coupled triple-continuum and discrete fracture model. J Petrol Sci Eng 174:49-69

Xu CY, Li PC, Lu ZW, Liu JW, Lu DT (2018) Discrete fracture modeling of shale gas flow considering rock deformation. J Natural Gas Sci Eng 52:507-514

Xu B, Wu Y, Cheng L, Huang SJ, Bai YH, Chen L, Liu YY, Yang YW, Yang LJ (2019) Uncertainty quantification in production forecast for shale gas well using a semi-analytical model. J Petrol Exploration Prod Technol 9:1963-1970

Yaghoubi A (2019) Hydraulic fracturing modeling using a discrete fracture network in the Barnett Shale. Int J Rock Mech Min Sci 119:98-108

Yuan JW, Jiang RZ, Cui YZ, Xu JC, Wang Q, Zhang W (2019) The numerical simulation of thermal recovery considering rock deformation in shale gas reservoir. Int J Heat Mass Transf 138:719-728

Zhang M, Yao J, Sun H, Zhao JL, Fan DY, Huang ZQ, Wang YY (2015) Triple-continuum modeling of shale gas reservoirs considering the effect of kerogen. J Natural Gas Sci Eng 24:252-263

Zhang W, Xu J, Jiang R (2017) Production forecast of fractured shale gas reservoir considering multi-scale gas flow. J Petrol Exploration Prod Technol 7:1071-1083

Zhang RH, Zhang LH, Tang HY, Chen SN, Zhao YL, Wu JF, Wang KR (2019) A simulator for production prediction of multistage fractured horizontal well in shale gas reservoir considering complex fracture geometry. J Natural Gas Sci Eng 67:14-29

Zheng JT, Ju Y, Liu HH, Zheng LG, Wang M (2016) Numerical prediction of the decline of the shale gas p roduction rate with considering the geomechanical effects based on the two-part Hooke's model. Fuel 185:362-369

Publisher's Note Springer Nature remains neutral with regard to jurisdictional claims in published maps and institutional affiliations. 